\title{
STATIC AND FATIGUE STRUCTURAL TESTS FOR EADS-CASA
}

\author{
Sebastian Szałkowski, Marcin Gębski \\ Institute of Aviation, Warsaw, Poland
}

\begin{abstract}
Summary
The paper presents structural tests of Airbus aircraft subcomponents which have been carried out at the Institute of Aviation in Warsaw to the order of EADS CASA in Madrid since 2004. Subcomponents of A318 and A400M aircraft were tested. Short descriptions of tested specimens, test set-up and test methods are included.
\end{abstract}

Static and fatigue structural tests of Airbus aircraft subcomponents have been carried out at the Institute of Aviation in Warsaw to the order of EADS CASA in Madrid.

The Institute of Aviation designed and built the test set-up and installed the hydraulic loading system, the control system (MTS Aero 90) and the measurement and the data acquisition system for all tests.

During the years 2004 - 2005 tests of the A318 fan-cowl subcomponents (doors) were carried out. Specimens consisted of hinge fitting or latch housing joined to representative panels of the surrounding area, including beams and stiffeners. Two similar specimens of each element were manufactured, one for static tests and the other for fatigue tests. The specimens were made mainly of steel and aluminum alloys.

Figure 1. shows the test set-up with hinge fitting specimen (one of the configurations) and Figure 2. shows the test set-up with latch housing specimen. About 140 channels for the strain gauges and 3 displacement transducers for both specimens were required to measure behavior of the specimen structures during the static tests as well as the fatigue tests.

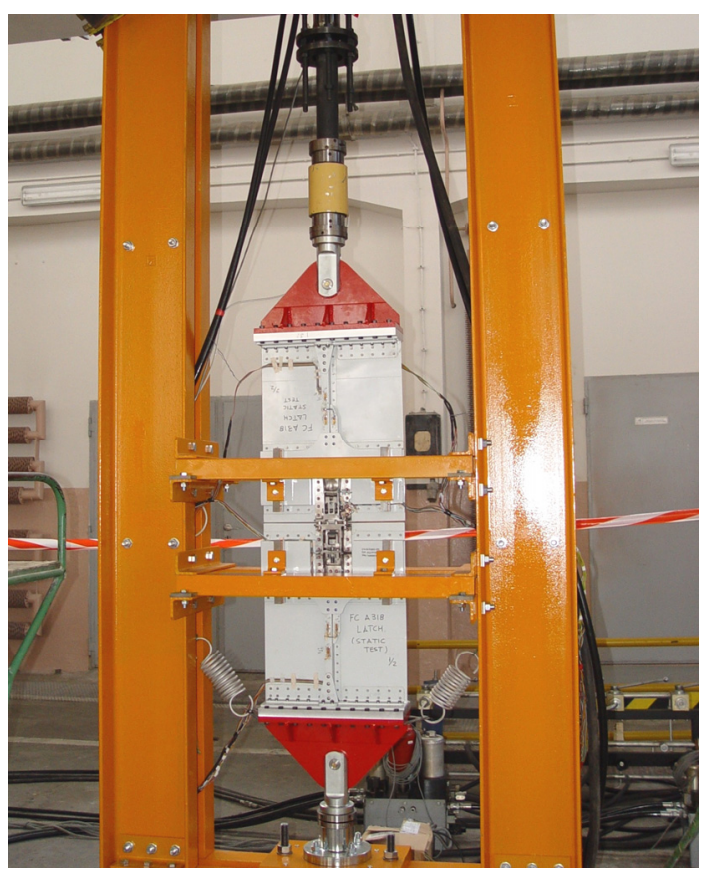

Fig. 1. Test set-up with the A318 fan-cowl door hinge fitting specimen. 


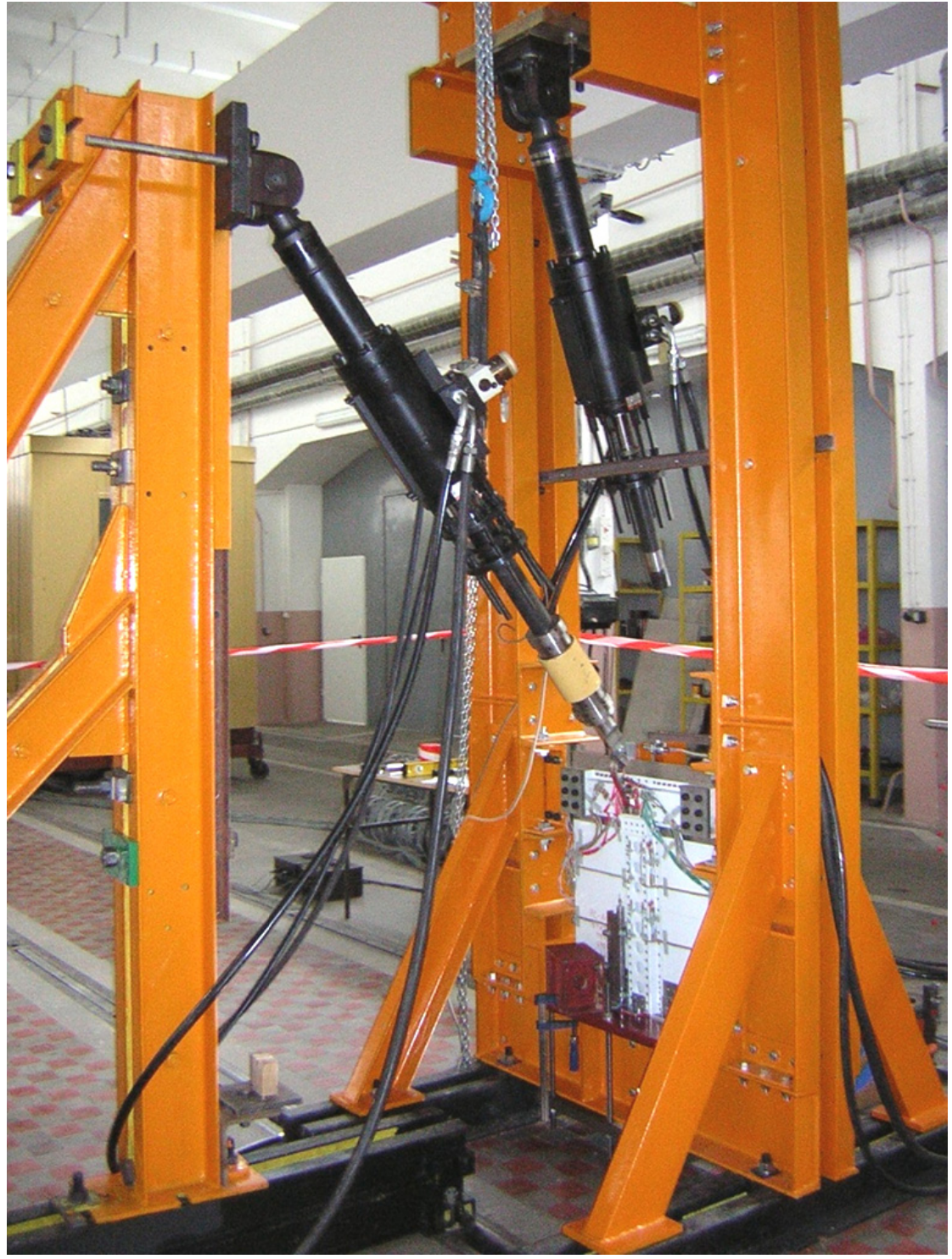

Fig. 2. Test set-up with the A318 fan-cowl door latch housing specimen.

The static tests were performed up to the limit load and then to the ultimate load and failure of the specimens. Both specimens successfully withstood required limit and ultimate loads.

The fatigue tests consisted of three phases: fatigue, damage tolerance and residual strength test. The inspection program included visual inspections and non-destructive inspections (high frequency eddy current method). Both specimens successfully withstood limit loads during residual strength test after damage tolerance phase. Both static and fatigue tests were carried out at room temperature.

During the years 2006 - 2008 tests of the A400M engine cowl subcomponents (doors) were carried out. Specimens consisted of titanium hinge fitting or latch housing joined to representative carbon fiber reinforced plastic (CFRP) panels of the surrounding area. Static test specimens included artificial defects and damages on the CFRP panels. Together 5 static tests and 1 fatigue test were carried out.

Figure 3. shows the test set-up with hinge fitting specimen (one of the configurations) and Figure 4. shows the test set-up with latch housing specimen. Tens of channels for the strain gauges and 3 displacement transducers for each specimen were required to measure behavior of the specimen structures during the static tests as well as the fatigue tests. 


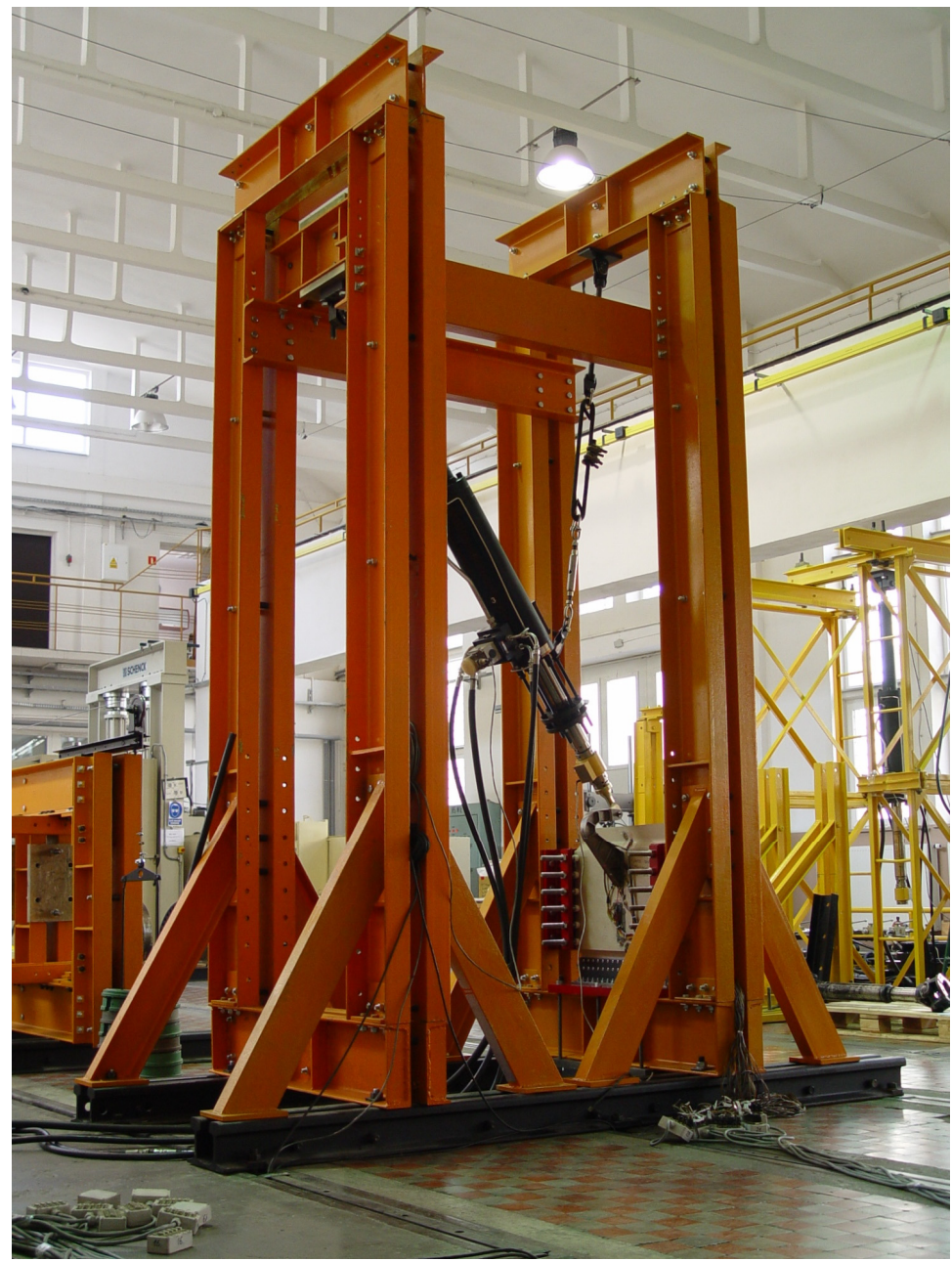

Fig. 3. Test set-up with the A400M engine cowl door hinge fitting specimen.

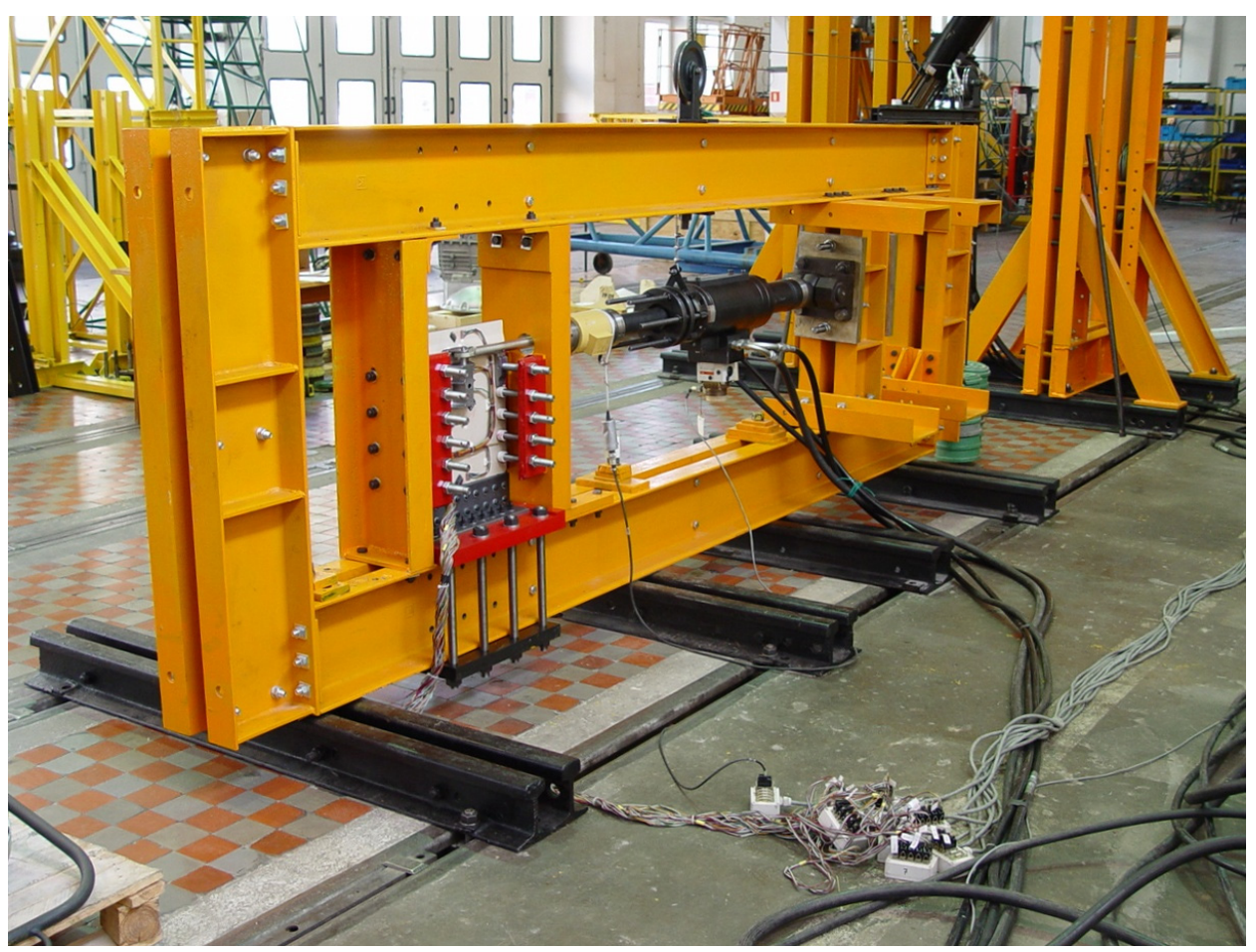

Fig. 4. Test set-up with the A400M engine cowl door latch housing specimen. 
The static tests were performed up to the limit load and then to the ultimate load and failure of the specimens. Specimens were inspected visually and with NDT (high frequency eddy current method for metallic parts and ultrasonic method for CFRP panels). All 5 specimens successfully withstood required limit and ultimate loads.

The fatigue test was concerned with the metallic parts of the specimen and consisted of three phases: fatigue, damage tolerance and residual strength test. The inspection program included visual inspections and non-destructive inspections (high frequency eddy current method for metallic parts). The specimen successfully withstood limit loads during residual strength test after damage tolerance phase. Both static and fatigue tests were carried out at room temperature.

At present, certification tests of actuator hinge fitting of A400M vertical tail plane (VTP) is under preparation at the Institute of Aviation. One specimen will be tested both under static and fatigue loads. Specimen consists of the fitting and representative part of the VTP carbon fiber composite box. Figure 5. shows designed test set-up with the specimen.

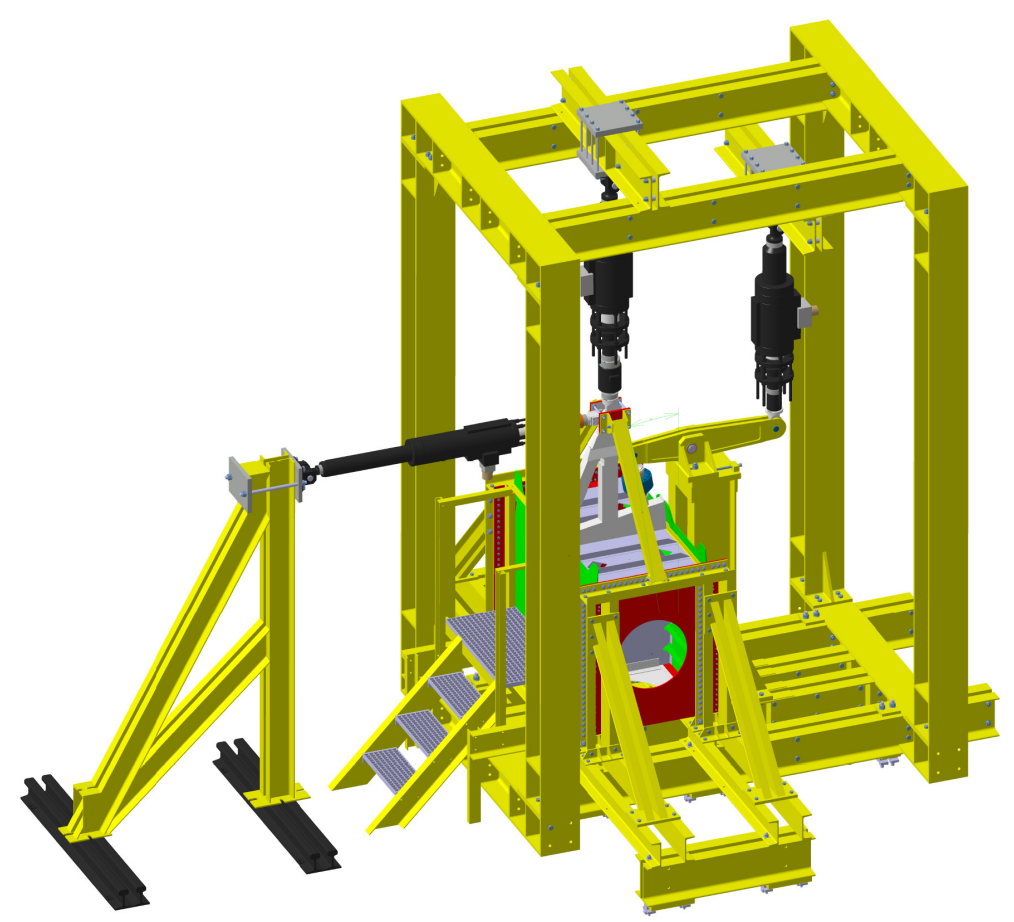

Fig. 5. Test set-up with the A400M VTP actuator hinge fitting specimen. 